\title{
Antimony in blood and urine of infants
}

\author{
A Cullen, B Kiberd, T Matthews, P Mayne, H T Delves, M O'Regan
}

\begin{abstract}
Aim-To establish a reference range for antimony in the serum and urine of infants in the first year of life.

Methods-100 infants were selected randomly from the population. Each infant had a single blood and urine sample taken. Antimony was assayed using inductively coupled plasma mass spectrometry.

Results-The reference range for antimony in the serum of infants in the first year of life was established as $0.09-0.25 \mu \mathrm{g} / \mathrm{l}$. The upper $95 \%$ centile for urinary antimony, corrected for creatinine, in the same population was $2.6 \mathrm{ng} / \mathrm{mg}$ creatinine. There was a very weak correlation between the serum and urine concentrations.

Conclusions-This study confirms the presence of low concentrations of antimony in the serum and urine of healthy infants.

(F Clin Pathol 1998;51:238-240)
\end{abstract}

Department of

Paediatrics, University

College Dublin,

The Children's

Hospital, Temple

Street, Dublin 1,

Ireland

A Cullen

T Matthews

National Sudden

Infant Death Register,

The Irish Sudden

Infant Death

Association, George's

Hall, Temple Street,

Dublin 1, Ireland

B Kiberd

Department of Clinical Biochemistry,

The Children's

Hospital, Temple

Street, Dublin 1,

Ireland

P Mayne

Department of Clinical

Biochemistry,

University of

Southampton SO16

6YD, UK

H T Delves

Department of

Statistics, Trinity

College, Dublin 2 ,

Ireland

M O'Regan

Correspondence to:

Dr Cullen.

Accepted for publication

11 November 1997
Keywords: antimony; sudden infant death syndrome; blood; urine

The sudden infant death syndrome (SIDS) is any death of an infant or young child that is unexpected by history and in which a thorough postmortem examination fails to demonstrate an adequate cause of death. ${ }^{1}$ Despite a recent reduction in rates of SIDS, this syndrome remains the leading cause of death between 4 weeks and 1 year of age. ${ }^{2}$ Although many theories have been proposed to explain the aetiology of SIDS, no one underlying cause has been identified. The hypothesis that antimony played a role in the SIDS was first proposed in 1990 when it was suggested that microbial generation of toxic gases from antimony, arsenic, and phosphorous based additives, used as fire retardants in cot mattresses, resulted in the poisoning of susceptible infants. ${ }^{3}$ It was claimed that this hypothesis was supported by the observation that the concentrations of antimony in the blood of three infants dying from SIDS were $1.9,2.8$, and $4.6 \mathrm{ng} / \mathrm{ml}$; concentrations that were above a reference range of $0.85 \mathrm{ng} / \mathrm{ml}$. ${ }^{4}$ However, there were no reported attempts to control sample collection and/or storage procedures to minimise contamination with antimony. Further evidence for the toxic gas theory was cited when investigators for the Cook Report (Central Television, 1994) confirmed detectable levels of antimony in liver samples of 22 of 41 infants who died of SIDS and only one of 15 control infants. Serum samples from 19 of the 39 SIDS cases and two of the 13 control cases were also positive. Tests of hair samples from living infants found that some had much higher concentrations of anti- mony than their mothers, suggesting an environmental exposure unique to infants. ${ }^{5}$ Since then, the data in the literature have been conflicting, with some authors reporting detectable concentrations of antimony in the liver of infants who died from SIDS compared with controls, ${ }^{6}$ while others have been unable to confirm this. ${ }^{7}$ Although much debate continues regarding the role of antimony in SIDS, there are no published data on the expected concentration of antimony in either tissue or body fluid samples of infants. This study was undertaken to establish a reference range for antimony for blood and urine in infants under 1 year old.

\section{Methods}

To ensure equal representation across the first year of life, the study group consisted of infants randomly selected from the following age categories - the newborn period, 3 months, 6 months, 9 months, and 12 months. Infants were selected from the Birth Register of the Eastern Health Board, an area incorporating Dublin and surrounding counties and accounting for one third of all births in the Republic of Ireland each year. A particular day of each month for five consecutive months (November 1995 to March 1996) was designated and infants who were exactly 10 days, 8 weeks, 20 weeks, 33 weeks, or 48 weeks on that day were eligible for selection. Eight children from each category were selected. There were no exclusion criteria. It was hoped that it would be possible to interview the parents of infants who were aged 2 weeks to 6 weeks, 8 weeks to 16 weeks, 20 weeks to 28 weeks, 33 weeks to 41 weeks, and finally 48 weeks to 56 weeks. Letters were sent to the families requesting participation in the study, which was entirely voluntary. Of 183 letters sent, 100 infants were enrolled (response rate 55\%). Each family, in association with one researcher (AC), completed a detailed questionnaire on sociodemographic data, the pregnancy, the infant's medical history, environmental characteristics, and current parenting practices, including details on the cot mattress being used. In addition, each child had a single blood and urine sample taken.

Blood samples of 3-5 $\mathrm{ml}$ were collected by venepuncture into $10 \mathrm{ml}$ polypropylene tubes (Sarstedt, Nuembrect, Germany), which were preservative free, and washed with $10 \% \mathrm{HCl}$ before use. The samples were centrifuged (2000 $\times g, 10$ minutes) and the serum was transferred into $3.5 \mathrm{ml}$ acid washed polypropylene tubes. Samples were separated and frozen at $-70^{\circ} \mathrm{C}$ within two hours of collection.

The urine specimens were collected using self adhesive plastic bags (Focal Corporation, 
Table 1 Mean (SD) serum antimony concentrations in 100 healthy infants

\begin{tabular}{lll}
\hline Age range & $\begin{array}{l}\text { Number of } \\
\text { infants }\end{array}$ & Antimony $(\mu g / l)$ \\
\hline 2-6 weeks & $17^{\star}$ & $0.16(0.03)$ \\
8-16 weeks & 16 & $0.16(0.03)$ \\
20-28 weeks & 18 & $0.18(0.04)$ \\
33-41 weeks & $22 \dagger$ & $0.17(0.05)$ \\
48-56 weeks & $27^{\star}$ & $0.18(0.04)$ \\
\hline
\end{tabular}

^Including one infant outside the age range; fincluding two infants outside the age range.

Tokyo, Japan) applied to the infants' perineum, transferred using $5 \mathrm{ml}$ plastic syringes (BectonDickinson, New Jersey, USA) into $30 \mathrm{ml}$ screw capped polystyrene containers (LIP, West Yorkshire, UK), and frozen as above within two hours of voiding.

A standard model Perkin-Elmer/Sciex 5000 inductively coupled plasma mass spectrometer (Perkin-Elmer-Sciex Inc, Toronto, Canada) was used to measure antimony in urine and serum. Each specimen was analysed in duplicate and prepared for analysis by aqueous dilution of $200 \mu \mathrm{l}$ volumes, with the addition of indium as an internal standard. Matrix matched standards were used for calibration and prepared by the addition of $0,0.25,0.5$, $1.0,2.0,5.0$, and $10.0 \mu \mathrm{g} / 1$ to an appropriate control sample, such as bovine serum or whole blood or urine from non-smoking adults. The calibration curves were linear over this range and all data points showed good proximity to the regression lines-over the nine month study period, $\mathrm{r}^{2}$ ranged from 0.9954 to 0.9995 for three blood calibrations, 0.9962 to 1.000 for 16 serum calibrations, and 0.9871 to 0.9999 for 12 urine calibrations.

Stringent internal quality control procedures were used. These consisted of analysing one set of two or three internal quality control specimens for each five duplicate test specimens. The internal quality control specimens were: unspiked human whole blood $(n=2)$, with antimony at 0.57 and $0.78 \mu \mathrm{g} / \mathrm{l}$; unspiked bovine sera $(\mathrm{n}=2)$, with antimony at 0.17 and $0.57 \mu \mathrm{g} / \mathrm{l}$; and human urine $(\mathrm{n}=3)$, one unspiked with a mean of $0.1 \mu \mathrm{g} / \mathrm{l}$, and two spiked with antimony to give means of 0.46 and $1.03 \mu \mathrm{g} / \mathrm{l}$. The precision (coefficients of variations) of the analyses were similar for all three specimens, ranging from $21 \%$ at $0.12 \mu \mathrm{g} / 1$ to $4.2 \%$ at $0.96 \mu \mathrm{g} / 1$. The detection limit (three standard deviations (SDs) of blank measurements) was $0.01 \mu \mathrm{g} / 1$ for all three types of sample.

Urinary creatinine measurements were made colorimetrically using the standard Jaffe

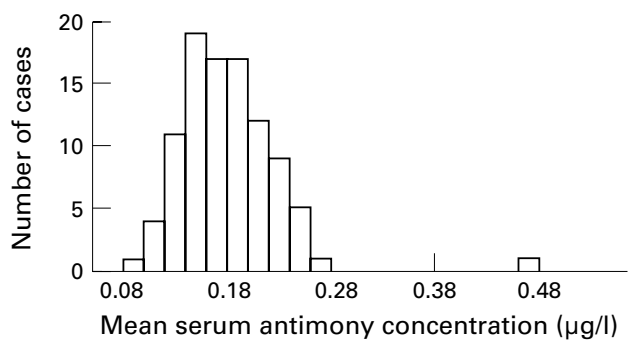

Figure 1 Mean serum antimony concentrations in 100 healthy infants reaction and a DAX automated analysis system.

The study was approved by the Scientific Advisory Committee of the Irish Sudden Infant Death Association and the Ethical Committee of The Children's Hospital, Temple Street. Informed consent was obtained from the accompanying parent/guardian before participation.

\section{Results}

POPULATION PROFILE

The profile of the population is outlined in table 1. Four infants fell outside the designated age ranges.

\section{ANTIMONY CONCENTRATIONS IN BLOOD AND} URINE

Of the 100 children studied, 97 serum samples were obtained and analysed. The data were approximately normally distributed (fig 1). Excluding the one outlier, the reference range for antimony in serum was $0.09-0.25 \mu \mathrm{g} / 1$ (mean $\pm 1.96 \mathrm{SD}$ ).

Because infants are known to concentrate urine poorly, the urinary antimony concentrations were corrected for urinary creatinine in 85 cases. In five cases, antimony was not detected, and for the purpose of analysis these cases were assigned the lowest value possible. The median was $0.42 \mathrm{ng} / \mathrm{mg}$ creatinine, the interquartile range was $0.64 \mathrm{ng} / \mathrm{mg}$ creatinine, and $95 \%$ of the cases had corrected urinary antimony concentrations of $<2.6 \mathrm{ng} / \mathrm{mg}$ creatinine.

After omitting the high serum value, there was a very weak correlation between the serum concentrations and $\log$ urine concentrations (correlation coefficient 0.24). Antimony concentrations in serum and urine were unrelated to the age or sex of the infant, paternal social class or occupation, medical coverage status of the family, or the type of mattress used.

\section{Discussion}

The role of antimony in SIDS has yet to be elucidated. It was essential to establish a reference range in a healthy infant population so that postmortem concentrations can be better interpreted. Some work has been done on the expected range of antimony in adults, but there have been no published data on the range in a paediatric population. Ludersdorf et al, studying occupational exposure to antimony, reported a range of antimony in whole blood of $0.3-1.7 \mu \mathrm{g} / 1$ (median $0.6 \mu \mathrm{g} / \mathrm{l}$ ) in a group of 51 unexposed adults. ${ }^{8}$ Kasperek et al reported mean (SD) concentrations in plasma of 0.52 (0.19) $\mu \mathrm{g} / 1,{ }^{9}$ and Wester, in a study on hypertensive patients, reported concentrations of antimony in serum of $0.75(0.51) \mu \mathrm{g} / 1 .{ }^{10}$ Serum was the body fluid analysed in the Cook Report and values $>1.0 \mu \mathrm{g} / \mathrm{l}$ were felt to indicate undue exposure (A Taylor, personal communication). The reference range of $0.09-0.25 \mu \mathrm{g} / 1$ for antimony in the serum of infants under 1 year of age confirms that there are negligible amounts of antimony in the serum of Irish infants with concentrations even lower than those detected in the adult population. One serum value $(0.47 \mu \mathrm{g} / \mathrm{l})$ did fall outside the ref- 
erence range and was confirmed on repeat testing. No explanation for this was found and there was nothing in the history to suggest that this infant had been unduly exposed to antimony in the environment.

Ludersdorf et al also analysed urine for antimony in eight adults that had not been occupationally exposed to antimony. He quoted a range of $0.2-0.7 \mu \mathrm{g} / 1,{ }^{8}$ comparable to our value of $<0.9 \mu \mathrm{g} / \mathrm{l}$ in urine uncorrected for creatinine.

It has been suggested that the concentrations of antimony in the urine may be a useful marker to monitor exposure to antimony. ${ }^{4}$ However, in our study, the lack of any correlation between serum and urine concentrations of antimony suggests that urine samples cannot be used to predict serum concentrations.

Antimony is a naturally occurring metal that is uniformly present throughout the environment. With sufficiently sensitive analytical techniques, it is possible to demonstrate the presence of antimony in the air, soil, and water. The most likely source of antimony exposure in humans is presumed to be the diet, with an estimated 10-23 $\mu \mathrm{g}$ of antimony being ingested daily. ${ }^{11} \mathrm{~A}$ recent study has also suggested that environmental dust is an important source in infants, contributing in excess of $1 \mu \mathrm{g}$ a day. ${ }^{12}$ Despite the suggestion by Richardson that fire retardants in cot mattresses contributed to the levels of antimony detected in the serum of infants, there was no evidence in this study to suggest that antimony concentrations in serum or in urine varied according to the type of mattress used, nor indeed did it vary according to a number of other parenting practices including smoking.
In conclusion, the information obtained to date confirms low concentrations of antimony in the serum and urine of healthy Irish infants. There was no correlation between these concentrations and numerous environmental factors including cot mattresses. It is hoped that this information will be of value when interpreting the concentration of antimony in tissue samples of SIDS victims.

The National Sudden Infant Death Register of the Irish Sudden Infant Death Association funded by the National Lottery through the Department of Health.

1 Bergman AB, Beckwith JB, Ray CG. Proceedings of the second international conference on causes of sudden infant death syndrome in infants. Seattle: University of Washington Press, 970:17-18.

2 Hoffmann HJ, Hillman LS. Epidemiology of the sudden infant death syndrome: maternal, neonatal and postneonatal risk factors. Clinics Perinatol 1992;19:717-37.

3 Richardson BA. Cot mattress biodeterioration and SIDS [letter]. Lancet 1990;335:670.

4 Richardson BA. Sudden infant death syndrome: a possible primary cause. f Forens Sci Soc 1994;34:199-204.

5 Fleming PJ, Cooke M, Chantler SM, et al. Fire retardants, biocides, plasticisers, and sudden infant deaths. BMf 1994;309:1594-5.

6 Taylor A. Antimony, cot mattresses and SIDS [letter]. Lancet 1996;347:616.

7 Howatson AG, Patrick WJA, Fell GS, et al. Cot mattresses Howatson AG, Patrick WJA, Fell GS, et al. Cot mattresses
and sudden infant death syndrome [letter]. Lancet and sudden infant

8 Ludersdorf R, Fuchs A, Mayer P, et al. Biological assessment of exposure to antimony and lead in the glass producing industry. Int Arch Occup Environ Health 1987;59:469-74.

9 Kasperek K, Iyengar G, Kiem J, et al. Elemental composition of platelets. Part III. Determination of Ag, Au, Cd, Co, $\mathrm{Cr}, \mathrm{Cs}, \mathrm{Mo}, \mathrm{Rb}, \mathrm{Sb}$, and Se in normal human platelets by neutron activation analysis. Clin Chem 1979;25:711-15.

10 Wester PO. Trace elements in serum and urine from hypertensive patients before and during treatment with chlorthalidone. Acta Med Scan 1973;194:502-12.

11 Elinder CG, Friberg L. Antimony. In: Friberg L, Norberg F, Vouk VB, eds. The handbook on the toxicology of metals. 2nd 12 Thompson M, Thornton I. Antimony in the domestic environment and SIDS. Environ Tech 1997;18:117-19 